\title{
Comparing bias correction methods in downscaling meteorological variables for a hydrologic impact study in an arid area in China
}

\author{
G. H. Fang ${ }^{1,2,3}$, J. Yang ${ }^{1,4}$, Y. N. Chen ${ }^{1}$, and C. Zammit ${ }^{4}$ \\ ${ }^{1}$ State Key Laboratory of Desert and Oasis Ecology, Xinjiang Institute of Ecology and Geography, \\ Chinese Academy of Sciences, Xinjiang, China \\ ${ }^{2}$ University of Chinese Academy of Sciences, Beijing, China \\ ${ }^{3}$ Department of Geography, Ghent University, Ghent, Belgium \\ ${ }^{4}$ National Institute of Water and Atmospheric Research, Christchurch, New Zealand \\ Correspondence to: J. Yang (yangjing@ms.xjb.ac.cn)
}

Received: 6 October 2014 - Published in Hydrol. Earth Syst. Sci. Discuss.: 13 November 2014

Revised: 8 May 2015 - Accepted: 8 May 2015 - Published: 2 June 2015

\begin{abstract}
Water resources are essential to the ecosystem and social economy in the desert and oasis of the arid Tarim River basin, northwestern China, and expected to be vulnerable to climate change. It has been demonstrated that regional climate models (RCMs) provide more reliable results for a regional impact study of climate change (e.g., on water resources) than general circulation models (GCMs). However, due to their considerable bias it is still necessary to apply bias correction before they are used for water resources research. In this paper, after a sensitivity analysis on input meteorological variables based on the Sobol' method, we compared five precipitation correction methods and three temperature correction methods in downscaling RCM simulations applied over the Kaidu River basin, one of the headwaters of the Tarim River basin. Precipitation correction methods applied include linear scaling (LS), local intensity scaling (LOCI), power transformation (PT), distribution mapping (DM) and quantile mapping $(\mathrm{QM})$, while temperature correction methods are LS, variance scaling (VARI) and DM. The corrected precipitation and temperature were compared to the observed meteorological data, prior to being used as meteorological inputs of a distributed hydrologic model to study their impacts on streamflow. The results show (1) streamflows are sensitive to precipitation, temperature and solar radiation but not to relative humidity and wind speed; (2) raw RCM simulations are heavily biased from observed meteorological data, and its use for streamflow simulations results in large biases from observed streamflow, and all bias correction methods effectively improved these simulations; (3) for precipitation,
\end{abstract}

PT and QM methods performed equally best in correcting the frequency-based indices (e.g., standard deviation, percentile values) while the LOCI method performed best in terms of the time-series-based indices (e.g., Nash-Sutcliffe coefficient, $R^{2}$ ); (4) for temperature, all correction methods performed equally well in correcting raw temperature; and (5) for simulated streamflow, precipitation correction methods have more significant influence than temperature correction methods and the performances of streamflow simulations are consistent with those of corrected precipitation; i.e., the PT and QM methods performed equally best in correcting flow duration curve and peak flow while the LOCI method performed best in terms of the time-series-based indices. The case study is for an arid area in China based on a specific RCM and hydrologic model, but the methodology and some results can be applied to other areas and models.

\section{Introduction}

In recent decades, the ecological situation of the Tarim River basin in China has seriously degraded, especially in the lower reaches of the Tarim River due to water scarcity. In the meantime, climate change is significant in this region with an increase in temperature at a rate of $0.33 \sim 0.39^{\circ} \mathrm{Cdecade}^{-1}$ and a slight increase in precipitation (Li et al., 2012) over the past 5 decades. Under the context of regional climate change, water resources in this region are expected to be more unstable and ecosystems are likely to suffer from severe wa- 
ter stress because the hydrologic system of the arid region is particularly vulnerable to climate change (Arnell et al., 1992; Shen and Chen, 2010; Wang et al., 2013). The impact of climate change on the hydrologic system has already been observed and it is expected that the hydrological system will continue to change in the future (Liu et al., 2010, 2011; Chen et al., 2010). Therefore, projecting reliable climate change and its impact on hydrology are important to study the ecology in the Tarim River basin.

Only recently, efforts have been made to evaluate and project the impact of climate change on hydrology in the Tarim River basin. These studies include research on the relationships of meteorological variables and streamflow based on the historical measurements (e.g., Z. Chen et al., 2013; Xu et al., 2013) and use of the GCM (general circulation models) outputs to drive a hydrologic model to study potential climate change on water resources (Liu et al., 2010, 2011). The study of historical climate-hydrology relationships has limited applications on future water resources management, especially under the context of global climate change. Though GCMs have been widely used to study impacts of future climate change on hydrological systems and water resources, they are impeded by their inability to provide reliable information at the hydrological scales (Maraun et al., 2010; Giorgi, 1990). In particular, for mountainous regions, fine-scale information such as the altitude-dependent precipitation and temperature information, which is critical for hydrologic modeling, is not represented in GCMs (Seager and Vecchi, 2010). Therefore, recent studies tend to use the higher-resolution regional climate models (RCMs) to preserve the physical coherence between atmospheric and land surface variables (Bergstrom et al., 2001; Anderson et al., 2011). As such, when evaluating the impact of climate change on water resources on a watershed scale, the use of RCMs instead of GCMs is preferable since RCMs have proven to provide more reliable results for impact study of climate change on regional water resources than GCM models (Buytaert et al., 2010; Elguindi et al., 2011). However, the raw RCM simulations may be still biased especially in the mountainous regions (Murphy, 1999; Fowler et al., 2007), which makes the use of RCM outputs as direct input for hydrological model challenging. As a result it is of significance to properly correct the RCM-simulated meteorological variables before they are used to drive a hydrological model, especially in an arid region where the hydrology is sensitive to climate changes.

Several bias correction methods have been developed to downscale meteorological variables from the RCMs, ranging from the simple scaling approach to sophisticated distribution mapping (Teutschbein and Seibert, 2012). And their applicability in the arid Tarim River basin has not been investigated; therefore, evaluating and finding the appropriate bias correction method is necessary to evaluate the impact of climate change on water resources.

This study evaluates performances of five precipitation bias correction methods and three temperature bias correc-

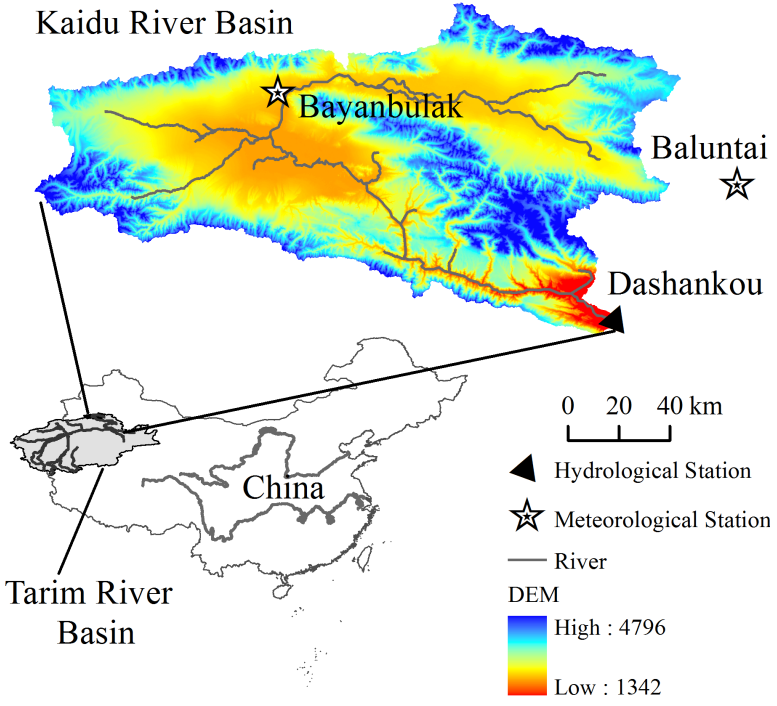

Figure 1. Location of the study area, two meteorological stations and one hydrological station.

tion methods in downscaling RCM simulations and applied to the Kaidu River basin, one of the most important headwaters of the Tarim River. These bias correction methods include the most frequently used bias correction methods. We compare their performances in downscaling precipitation and temperature and evaluate their impact on streamflow through hydrological modeling.

The paper is constructed as follows: Sect. 2 introduces the study area and data; Sect. 3 describes the bias correction methods for precipitation and temperature along with the hydrological model, sensitivity analysis method and result analysis strategy; Sect. 4 presents results and discussion, followed by conclusions in Sect. 5 .

\section{Study area and data}

\subsection{Study area and observed data}

The Kaidu River basin, with a drainage area of $18634 \mathrm{~km}^{2}$ above the Dashankou hydrological station, is located on the south slope of the Tianshan Mountains in northwestern China (Fig. 1). Its altitude ranges from 1342 to $4796 \mathrm{~m}$ above sea level (a.s.l.) with an average elevation of $2995 \mathrm{~m}$, and its climate is temperate continental with alpine climate characteristics. As one of the headwaters of the Tarim River, it provides water resources for agricultural activity and ecological environment of the oasis in the lower reaches. This oasis, with a population of over 1.15 million, is stressed by lack of water and water resources are the main factor constricting the development (Y. Chen et al., 2013). Therefore, projecting the impact of future climate change on water resources is urgent to the sustainable development of this region. 


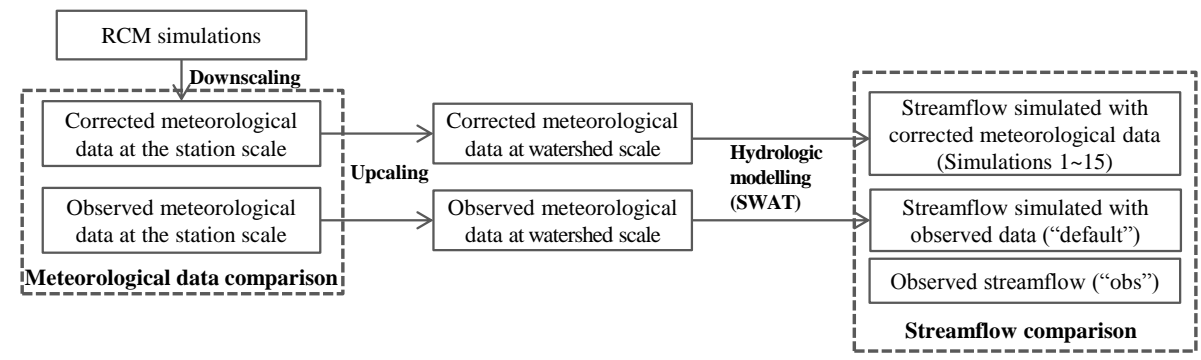

Figure 2. Flow chart of comparison procedure.

Daily observed meteorological data, including precipitation, maximum/minimum temperature, wind speed and relative humidity of two meteorological stations (Bayanbulak and Baluntai, stars in Fig. 1) are from the China Meteorological Data Sharing Service System (http://cdc.cma.gov.cn/). The mean annual maximum and minimum temperature at the Bayanbulak meteorological station are 3.1 and $-10.6^{\circ} \mathrm{C}$ and mean annual precipitation is $267 \mathrm{~mm}$; and generally precipitation falls as rain from May to September and as snow from October to April of the next year.

The observed streamflow data at the Dashankou hydrologic station (the triangle in Fig. 1) are from Xinjiang Tarim River basin Management Bureau. The average daily flow is around $110 \mathrm{~m}^{3} \mathrm{~s}^{-1}$ (equivalent to $185 \mathrm{~mm}$ of runoff per year), ranging from 15 to $973 \mathrm{~m}^{3} \mathrm{~s}^{-1}$.

\subsection{Simulated meteorological variables from the RCM}

GCM or RCM outputs are generally biased (Ahmed et al., 2013; Teutschbein and Seibert, 2012; Mehrotra and Sharma, 2012) and there is a need to correct these outputs before they are used for regional impact studies. The RCM outputs used in this study are based on the work done by Gao et al. (2013). In Gao et al. (2013), the RCM model (RegCM; Giorgi and Mearns, 1999) was driven by a global climate model BCC_CSM1.1 (Beijing Climate Center Climate System Model; Wu et al., 2013; Xin et al., 2013) at a horizontal resolution of $50 \mathrm{~km}$ over China.

The RCM outputs were validated with the observational data set (CN05.1) over China for the period from 1961 to 2005. The RCM outputs show reasonable simulation of temperature and precipitation in most parts of China except for some regions where our study area is located (for more details refer to Gao et al., 2013).

\section{Methodology}

Figure 2 shows the flow chart of the comparison procedure. First, the grid-based RCM simulation was downscaled to station scale using bias correction methods, and then the corrected meteorological data were compared to the observations at these two stations and to each other ("Meteorologi- cal data comparison" in Fig. 2). These station-based meteorological data were then upscaled to watershed scale with the precipitation and temperature lapse rates before they were used to drive the hydrological model (SWAT). Finally, the simulated streamflow driven by the corrected and observed meteorological data were compared to observed streamflow and to each other ("Streamflow comparison" in Fig. 2).

\subsection{Hydrologic model and sensitivity analysis}

SWAT (Soil and Water Assessment Tool; Arnold et al., 1998) is a distributed and time continuous watershed hydrologic model. The climatic input (driving force) consists of daily precipitation, maximum/minimum temperature, solar radiation, wind speed and relative humidity. To account for orographic effects on precipitation and temperature, elevation bands were used. Within each elevation band, the precipitation and temperature are estimated based on their lapse rates and elevation. For more details, refer to SWAT manuals (http://www.brc.tamus.edu/). SWAT has been being widely used for comprehensive modeling of the impact of management practices and climate change on the hydrologic cycle and water resources at a watershed scale (e.g., Arnold et al., 2000; Arnold and Fohrer, 2005; Setegn et al., 2011).

In this study, the SWAT model was firstly set up with available DEM (digital elevation model), land use, soil, and observed climate data, and then model parameters were calibrated with the observed streamflow data at the Dashankou Station. The simulation results show (1) model application with excellent performances for both the calibration $(1986 \sim 1989)$ and validation $(1990 \sim 2001)$ periods with daily NS (Nash-Sutcliffe coefficient; Nash and Sutcliffe, 1970; see the definition in Eq. 16) and $R^{2}$ values of over 0.80 , which is highly acceptable; (2) model parameters are reasonable and spatial patterns of precipitation and temperature are in agreement with other studies in the region (see more details in Fang et al., 2015). Figure 3 shows a comparison of mean hydrographs of the observed (obs) and simulated flows (default). This calibrated model hence provides a basis for evaluation of the impact of different correction methods on streamflow.

To study the relative importance of the five meteorological variables, the Sobol' sensitivity analysis method (Sobol', 
Table 1. Sensitivity indices of the five meteorological variables based on the Sobol' method.

\begin{tabular}{|c|c|c|c|c|}
\hline Factor $^{\mathrm{a}}$ & Meaning & $\begin{array}{l}\text { Factor } \\
\text { Range }\end{array}$ & $\begin{array}{r}\text { Main } \\
\text { effect } \\
S_{i}(\%)\end{array}$ & $\begin{array}{r}\text { Total } \\
\text { effect } \\
S_{T i}(\%)\end{array}$ \\
\hline a_tmp & Additive change to temperature & {$[-5,5]$} & 15.0 & 36.9 \\
\hline r_pcp & Relative change to precipitation & {$[-0.5,0.5]$} & 44.0 & 74.0 \\
\hline r_hmd & Relative change to humidity & {$[-0.5,0.5]$} & 0.0 & 0.0 \\
\hline r_slr & Relative change to solar radiation & {$[-0.5,0.5]$} & 7.7 & 22.6 \\
\hline r_wnd & Relative change to wind speed & {$[-0.5,0.5]$} & 0.3 & 0.9 \\
\hline
\end{tabular}

a Here, "a_" and "r_", respectively, mean an addictive and a relative change to the initial parameter values.

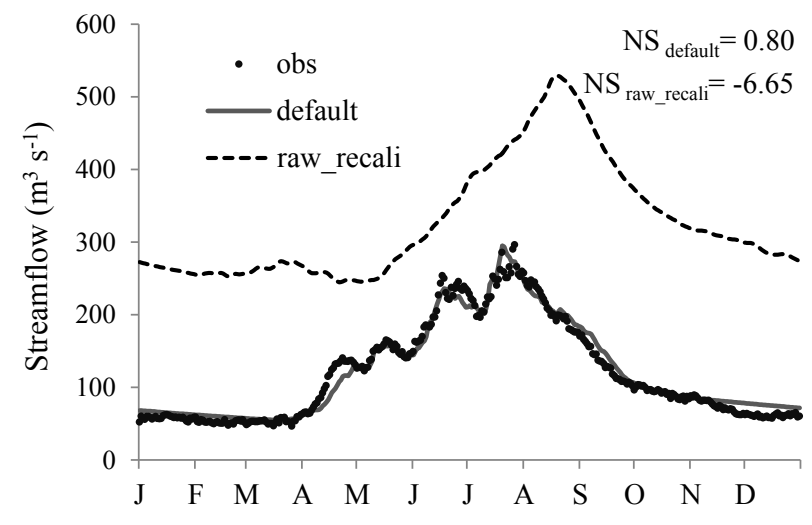

Figure 3. Mean annual hydrographs of observed streamflow (obs) and simulated streamflow using observed meteorological data (default) during the period of $1986 \sim 2001$ at the Dashankou Station. The simulated streamflow using raw RCM-simulated meteorological data after recalibration (raw_recali) is also plotted. The NS values are for the daily continuous data and not for the mean hydrograph.

2001) was applied. The Sobol' method is based on the decomposition of the variance $\mathrm{V}$ of the objective function:

$V=\sum_{i} V_{i}+\sum_{i} \sum_{j>i} V_{i j}+\cdots+V_{1,2, \cdots, n}$,

where

$V_{i}=\mathrm{V}\left(\mu\left(Y \mid X_{i}\right)\right)$,

$V_{i j}=\mathrm{V}\left(\mu\left(Y \mid X_{i}, X_{j}\right)\right)-V_{i}-V_{j}$,

and so on. Herein, $\mathrm{V}($.) denotes the variance operator, $V$ is the total variance, and $V_{i}$ and $V_{i j}$ are main variance of $X_{i}$ (the $i$ th factor of $X$ ) and partial variance of $X_{i}$ and $X_{j}$. Here factors $X$ are the changes applied to these five meteorological variables, respectively (see Table 1 for a list of these factors). In practice, normalized indices are often used as sensitivity measures:

$$
\begin{aligned}
S_{i} & =\frac{V_{i}}{V}, 1 \leq i \leq n, \\
S_{i j} & =\frac{V_{i j}}{V}, 1 \leq i<j \leq n, \\
S_{T i} & =S_{i}+\sum_{j} S_{i j}+\sum_{j} \sum_{k} S_{i j k}+\ldots \\
& +S_{1,2, \ldots, n}, 1 \leq i \leq n .
\end{aligned}
$$

Where $S_{i}, S_{i j}$ and $S_{T i}$ are the main effect of $X_{i}$, first order interaction between $X_{i}$ and $X_{j}$, and total effect of $X_{i} . S_{T i}$ ranges from 0 to 1 and denotes the importance of the factor to model output. The larger $S_{T i}$, the more important this factor is. The difference between $S_{T i}$ and $S_{i}$ denotes the significance of the interaction of this factor with other factors. As a result, the larger this difference, the more significant the interaction is.

\subsection{Bias correction methods}

In this study, five bias correction methods were used for precipitation, and three for temperature. These methods are listed in Table 2. All these bias correction methods were conducted on a daily basis from 1975 to 2005 .

\subsubsection{Linear scaling (LS) of precipitation and temperature}

The LS method aims to perfectly match the monthly mean of corrected values with that of observed ones (Lenderink et al., 2007). It operates with monthly correction values based on the differences between observed and raw data (raw RCMsimulated data in this case). Precipitation is typically corrected with a multiplier and temperature with an additive term on a monthly basis:

$$
\begin{aligned}
& P_{\text {cor }, \mathrm{m}, \mathrm{d}}=P_{\text {raw }, \mathrm{m}, \mathrm{d}} \times \frac{\mu\left(P_{\text {obs }, \mathrm{m}}\right)}{\mu\left(P_{\text {raw }, \mathrm{m}}\right)}, \\
& T_{\text {cor, } \mathrm{m}, \mathrm{d}}=T_{\text {raw }, \mathrm{m}, \mathrm{d}}+\mu\left(T_{\text {obs }, \mathrm{m}}\right)-\mu\left(T_{\text {raw }, \mathrm{m}}\right),
\end{aligned}
$$

where $P_{\text {cor,m,d }}$ and $T_{\text {cor,m,d }}$ are corrected precipitation and temperature on the $d$ th day of $m$ th month, and $P_{\text {raw,m,d }}$ and 
days, which may substantially distort the raw precipitation distribution, the correction is done on LOCI-corrected precipitation $P_{\mathrm{LOCI}, \mathrm{m}, \mathrm{d}}$ :

$$
\begin{gathered}
P_{\text {cor }, \mathrm{m}, \mathrm{d}}=F_{\mathrm{r}}^{-1}\left(F_{\mathrm{r}}\left(P_{\mathrm{LOCI}, \mathrm{m}, \mathrm{d}} \mid \alpha_{\mathrm{LOCI}, \mathrm{m}}, \beta_{\mathrm{LOCI}, \mathrm{m}}\right) \mid\right. \\
\left.\alpha_{\mathrm{obs}, \mathrm{m}}, \beta_{\mathrm{obs}, \mathrm{m}},\right)
\end{gathered}
$$

where $F_{\mathrm{r}}($.$) and F_{\mathrm{r}}^{-1}($.$) are the gamma \mathrm{CDF}$ (cumulative distribution function) and its inverse. $\alpha_{\mathrm{LOCI}, \mathrm{m}}$ and $\beta_{\mathrm{LOCI}, \mathrm{m}}$ are the fitted gamma parameters for the LOCI-corrected precipitation in a given month $m$, and $\alpha_{\mathrm{obs}, \mathrm{m}}$ and $\beta_{\mathrm{obs}, \mathrm{m}}$ are these for observations.

For temperature, the Gaussian distribution (or normal distribution) with mean $\mu$ and standard deviation $\sigma$ is usually assumed to fit temperature best (Teutschbein and Seibert, 2012):

$f_{N}(x \mid \mu, \sigma)=\frac{1}{\sigma \times \sqrt{2 \pi}} \times e^{\frac{-(x-\mu)^{2}}{2 \sigma^{2}}} ; x \in R$.

And then similarly the corrected temperature can be expressed as

$$
\begin{aligned}
& T_{\text {cor,m,d }}=F_{N}^{-1} \\
& \left(F_{N}\left(T_{\text {raw }, \mathrm{m}, \mathrm{d}} \mid \mu_{\text {raw }, \mathrm{m}}, \sigma_{\text {raw }, \mathrm{m}}\right) \mid \mu_{\text {obs }, \mathrm{m}}, \sigma_{\text {obs }, \mathrm{m}}\right),
\end{aligned}
$$

where $F_{N}\left(\right.$.) and $F_{N}^{-1}($.) are the Gaussian CDF and its inverse, $\mu_{\text {raw,m }}$ and $\mu_{\mathrm{obs}, \mathrm{m}}$ are the fitted and observed means for the raw and observed precipitation series at a given month $m$, and $\sigma_{\text {raw, } \mathrm{m}}$ and $\sigma_{\mathrm{obs}, \mathrm{m}}$ are the corresponding standard deviations, respectively.

\subsubsection{Quantile mapping (QM) of precipitation}

The QM method is a non-parametric bias correction method and is generally applicable for all possible distributions of precipitation without any assumption on precipitation distribution. This approach originates from the empirical transformation (Themeßl et al., 2012) and was successfully implemented in the bias correction of RCM-simulated precipitation (Sun et al., 2011; Themeß1 et al., 2012; J. Chen et al., 2013; Wilcke et al., 2013). It can effectively correct bias in the mean, standard deviation and wet-day frequency as well as quantiles.

For precipitation, the adjustment of precipitation using QM can be expressed in terms of the empirical CDF (ecdf) and its inverse $\left(\mathrm{ecdf}^{-1}\right)$ :

$P_{\text {cor }, \mathrm{m}, \mathrm{d}}=\operatorname{ecdf}_{\text {obs }, \mathrm{m}}^{-1}\left(\operatorname{ecdf}_{\text {raw }, \mathrm{m}}\left(P_{\text {raw }, \mathrm{m}, \mathrm{d}}\right)\right)$.

\subsection{Performance evaluation}

The performance evaluation of these correction methods is based on their abilities to reproduce precipitation, temperature, and streamflow simulated with a hydrological model (SWAT) driven by bias-corrected RCM simulations. When evaluating the ability to reproduce streamflow, streamflow is firstly simulated by running the hydrological model driven by 15 different combinations of corrected precipitation, $\max / \mathrm{min}$ temperature with different correction methods (these hydrologic simulations are then referred to as simulations 1-15, which are listed in Table 3) together with hydrologic simulations driven by observed meteorological data (default) and raw RCM simulation (raw). These 15 simulations were then compared with observed streamflows and default and raw.

The performance evaluation of precipitation, temperature and streamflow are as follows.

1. For corrected precipitation, frequency-based indices and time series performances are compared with observed precipitation data. The frequency-based indices include mean, median, standard deviation, 99th percentile, probability of wet days, and intensity of wet day while time-series-based metrics include NS, percent bias $\left(P_{\mathrm{BIAS}}\right), R^{2}$ and mean absolute error (MAE) defined as follows: where $Y_{i}^{\text {obs }}$ and $Y_{i}^{\text {sim }}$ are the $i$ th observed and simulated variables, $Y^{\text {mean }}$ is the mean of observed variables, and $n$ is the total number of observations.

$$
\begin{gathered}
\mathrm{NS}=1-\frac{\sum_{i=1}^{n}\left(Y_{i}^{\mathrm{obs}}-Y_{i}^{\mathrm{sim}}\right)^{2}}{\sum_{i=1}^{n}\left(Y_{i}^{\mathrm{obs}}-Y_{i}^{\mathrm{mean}}\right)^{2}} \\
P_{\mathrm{BIAS}}=\frac{\sum_{i=1}^{n}\left(Y_{i}^{\mathrm{obs}}-Y_{i}^{\mathrm{sim}}\right)}{\sum_{i=1}^{n}\left(Y_{i}^{\mathrm{obs}}\right)} \\
\mathrm{MAE}=\frac{\sum_{i=1}^{n}\left|Y_{i}^{\mathrm{obs}}-Y_{i}^{\mathrm{sim}}\right|}{n}
\end{gathered}
$$

NS indicates how well the simulation matches the observation and it ranges between $-\infty$ and 1 , with $\mathrm{NS}=1$ meaning a perfect fit. The higher this value, the more reliable the model is in comparison to the mean. $P_{\mathrm{BIAS}}$ measures the average tendency of the simulated data to their observed counterparts. Positive values indicate an overestimation of observation, while negative values indicate an underestimation. The optimal value of $P_{\text {BIAS }}$ is 0.0 , with low-magnitude values indicating accurate model simulations. MAE demonstrates the average model prediction error with less sensitivity to large errors.

2. For corrected temperature, frequency-based indices and time series performances are compared with observed temperature data. The frequency-based indices include mean, median, standard deviation, and 10th and 90th percentiles while time-series-based metrics include NS, $P_{\mathrm{BIAS}}, R^{2}$ and MAE.

3. For simulated streamflow driven by corrected RCM simulations, the frequency-based indices are visualized 
Table 3. Performances of simulated streamflows driven by raw RCM-simulated data (raw) and 15 combinations of bias-corrected precipitation and temperature data (denoted as numbers from 1 to 15 ) compared to the simulation driven by observed climate (default) during the period 1986 2001. For simulations 1-15, solar radiation is corrected with the LS method.

\begin{tabular}{|c|c|c|c|c|c|c|c|c|c|c|}
\hline & \multicolumn{2}{|c|}{ Bias correction method } & \multicolumn{4}{|c|}{ Daily } & \multicolumn{4}{|c|}{ Monthly } \\
\hline & Precipitation & Temperature & NS (-) & $P_{\text {BIAS }}(\%)$ & $R^{2}(-)$ & $\begin{array}{r}\text { MAE } \\
\left(\mathrm{m}^{3} \mathrm{~s}^{-1}\right)\end{array}$ & NS (-) & $P_{\mathrm{BIAS}}(\%)$ & $R^{2}(-)$ & $\begin{array}{r}\text { MAE } \\
\left(\mathrm{m}^{3} \mathrm{~s}^{-1}\right)\end{array}$ \\
\hline raw & raw & raw & -47.69 & 398.9 & 0.4 & 547.5 & -56.34 & 399.4 & 0.6 & 524.6 \\
\hline 1 & LS & $\mathrm{LS}$ & -2.66 & 106.2 & 0.5 & 150.1 & -3.09 & 106.4 & 0.7 & 140.2 \\
\hline 2 & LS & VARI & -2.43 & 103.5 & 0.5 & 145.4 & -2.85 & 103.7 & 0.7 & 135.9 \\
\hline 3 & $\mathrm{LS}$ & $\mathrm{DM}$ & -2.43 & 103.5 & 0.5 & 145.4 & -2.85 & 103.7 & 0.7 & 135.9 \\
\hline 4 & LOCI & $\mathrm{LS}$ & 0.49 & -8.0 & 0.5 & 56.0 & 0.70 & -7.9 & 0.7 & 38.2 \\
\hline 5 & LOCI & VARI & 0.50 & -8.6 & 0.5 & 55.6 & 0.70 & -8.6 & 0.7 & 38.1 \\
\hline 6 & LOCI & DM & 0.50 & -8.6 & 0.5 & 55.6 & 0.70 & -8.6 & 0.7 & 38.1 \\
\hline 7 & PT & $\mathrm{LS}$ & 0.38 & -3.3 & 0.4 & 61.7 & 0.64 & -3.3 & 0.7 & 41.4 \\
\hline 8 & PT & VARI & 0.39 & -4.1 & 0.5 & 61.3 & 0.65 & -4.1 & 0.7 & 41.1 \\
\hline 9 & PT & DM & 0.39 & -4.1 & 0.5 & 61.3 & 0.65 & -4.1 & 0.7 & 41.1 \\
\hline 10 & DM & LS & 0.41 & 3.6 & 0.5 & 60.3 & 0.66 & 3.6 & 0.7 & 40.5 \\
\hline 11 & DM & VARI & 0.42 & 2.8 & 0.5 & 9.5 & 0.67 & 2.9 & 0.7 & 40.0 \\
\hline 12 & DM & $\mathrm{DM}$ & 0.42 & 2.8 & 0.5 & 59.5 & 0.67 & 2.9 & 0.7 & 40.0 \\
\hline 13 & $\mathrm{QM}$ & LS & 0.39 & -2.6 & 0.5 & 61.3 & 0.65 & -2.6 & 0.7 & 40.9 \\
\hline 14 & $\mathrm{QM}$ & VARI & 0.40 & -3.4 & 0.5 & 60.8 & 0.65 & -3.4 & 0.7 & 40.7 \\
\hline 15 & $\mathrm{QM}$ & $\mathrm{DM}$ & 0.40 & -3.4 & 0.5 & 60.8 & 0.65 & -3.4 & 0.7 & 40.7 \\
\hline
\end{tabular}

using a box plot, exceedance probability curve. Timeseries-based metrics include NS, $P_{\mathrm{BIAS}}, R^{2}$ and MAE.

\section{Results and discussion}

\subsection{Initial streamflow simulation driven with raw RCM simulations and sensitivity analysis}

To illustrate the necessity of bias correction in climate change impact on hydrology, we recalibrated SWAT using the raw RCM simulations while keeping all SWAT parameters in their reasonable ranges. The assumption is that if the recalibrated hydrological model driven by the raw RCM simulations performs well and model parameters are reasonable, then there is no need for bias correction. The streamflow simulated by the recalibrated model was plotted in Fig. 3, and it systematically overestimates the observation with NS equals -6.65 . Therefore, it is necessary to correct the meteorological variables before they can be used for a hydrological impact study.

The Sobol' method was applied to study which meteorological variables should be corrected for hydrological modeling. Table 1 lists the sensitivity results for these five meteorological variables. As can be seen, precipitation is the most sensitive factor (the main effect $S_{i}$ is $44.0 \%$ and total effect $S_{T i}$ is $74.0 \%$ ), followed by temperature ( $S_{i}=15.0 \%$ and $\left.S_{T i}=36.9 \%\right)$ and solar radiation $\left(S_{i}=7.7 \%\right.$ and $S_{T i}=$ $22.6 \%$ ), and the interactions between these factors are large. Relative humidity and wind speed are insensitive in this case. This means precipitation, temperature and solar radiation need to be bias corrected before being applied to hydrologic models, while relative humidity and wind speed over the region do not need any correction.

\subsection{Evaluation of corrected precipitation and temperature}

The bias correction was done on RCM-simulated precipitation, $\mathrm{max} / \mathrm{min}$ temperature, and solar radiation (for solar radiation, the LS and VARI methods were used) for two meteorological stations: Bayanbulak and Baluntai. Results show that (1) for solar radiation, there is no significant difference for different correction methods (there the results are not shown); and (2) similar results were obtained for minimum temperature and maximum temperature, and for Bayanbulak and Baluntai. Therefore, we only listed and discussed results for Bayanbulak, and maximum temperature.

Table 4 lists the frequency-based statistics of observed (obs), raw RCM-simulated (raw) and corrected (denoted by the corresponding correction method) precipitation data at the Bayanbulak Station. This station has a daily mean precipitation of $0.73 \mathrm{~mm}$ or annual mean of $266 \mathrm{~mm}$ and precipitation falls in $32 \%$ of the days in a year with a mean intensity of $2.3 \mathrm{~mm}$. Compared to the observation, the raw RCM simulation deviates significantly from observations, with overestimation of all the statistics. All the bias correction methods improve the raw RCM-simulated precipitation; however, there are differences in their corrected statistics. LS method has a good estimation of the mean while it shows a large bias in other measures, e.g., it largely overestimated the probability of wet days (e.g., up to $41 \%$ overestimation) and un- 
Table 4. Frequency-based statistics of daily observed (obs), raw RCM-simulated (raw) and bias-corrected precipitations at the Bayanbulak Station.

\begin{tabular}{lrrrrrr}
\hline & $\begin{array}{r}\text { Mean } \\
(\mathrm{mm})\end{array}$ & $\begin{array}{r}\text { Median } \\
(\mathrm{mm})\end{array}$ & $\begin{array}{r}\text { Standard } \\
\text { deviation }(\mathrm{mm})\end{array}$ & $\begin{array}{r}\text { 99th percentile } \\
(\mathrm{mm})\end{array}$ & $\begin{array}{r}\text { Probability of } \\
\text { wet days }(\%)\end{array}$ & $\begin{array}{r}\text { Intensity of } \\
\text { wet day }(\mathrm{mm})\end{array}$ \\
\hline obs & 0.73 & 0.0 & 2.4 & 12.4 & 32 & 2.3 \\
raw & 2.87 & 1.4 & 4.1 & 19.7 & 86 & 3.3 \\
LS & 0.73 & 0.2 & 1.5 & 7.6 & 73 & 1.0 \\
LOCI & 0.73 & 0.0 & 1.7 & 8.1 & 32 & 2.3 \\
PT & 0.73 & 0.0 & 2.4 & 11.4 & 32 & 2.3 \\
DM & 0.78 & 0.0 & 2.3 & 11.5 & 32 & 2.5 \\
QM & 0.73 & 0.0 & 2.4 & 12.4 & 32 & 2.3 \\
\hline
\end{tabular}

derestimated the standard deviation (up to $0.9 \mathrm{~mm}$ underestimation). The LOCI method provides a good estimation in the mean, median, wet-day probability and wet-day intensity; however, there is a slight underestimation in the standard deviation and therefore the 99th percentile. Compared to LS and LOCI, the PT method performs well in all these metrics. The DM method has a slight overestimation of the mean and an underestimation of standard deviation. This means that precipitation does not follow the assumed gamma distribution. On the contrary, the QM method does not have this assumption and it provides an excellent estimation of these statistics. These results are consistent with previous studies (Themeßl et al., 2011, 2012; Wilcke et al., 2013; Graham et al., 2007) but are different from the research by Piani et al. (2010), who found that performance of the DM method is unexpectedly well for the humid Europe region. This discrepancy can be partly attributed to the precipitation regime for different regions since a better fit of the assumed distribution leads to a better performance of DM.

Table 5 lists the frequency-based statistics of observed (obs), raw RCM-simulated (raw) and corrected (denoted by the corresponding method) maximum temperature data at the Bayanbulak Station. The mean and standard deviation of obs are 3.1 and $14.5^{\circ} \mathrm{C}$, with the 90th percentile being $19.2^{\circ} \mathrm{C}$. Analysis of the raw indicates deviation from obs, with an overestimation of the mean, and underestimations of the median, standard deviation, and 90th percentile. All three correction methods correct biases in the raw and improve estimations of the statistics. LS has a correct estimation of mean but slight underestimations of the median and standard deviation, while VARI and DM have good estimations of all the frequency-based statistics. These results confirm the study by Teutschbein and Seibert (2012); i.e., the LS method does not adjust the standard deviation and the percentiles while the VARI and DM methods do.

Figure 4 shows the exceedance probability curves of the observed and corrected precipitation and temperature. For precipitation, the raw RCM simulations are heavily biased (as also shown by statistics in Table 4). All correction methods effectively, but in different extent, correct biases in raw precipitation. The LS method underestimates the high pre-

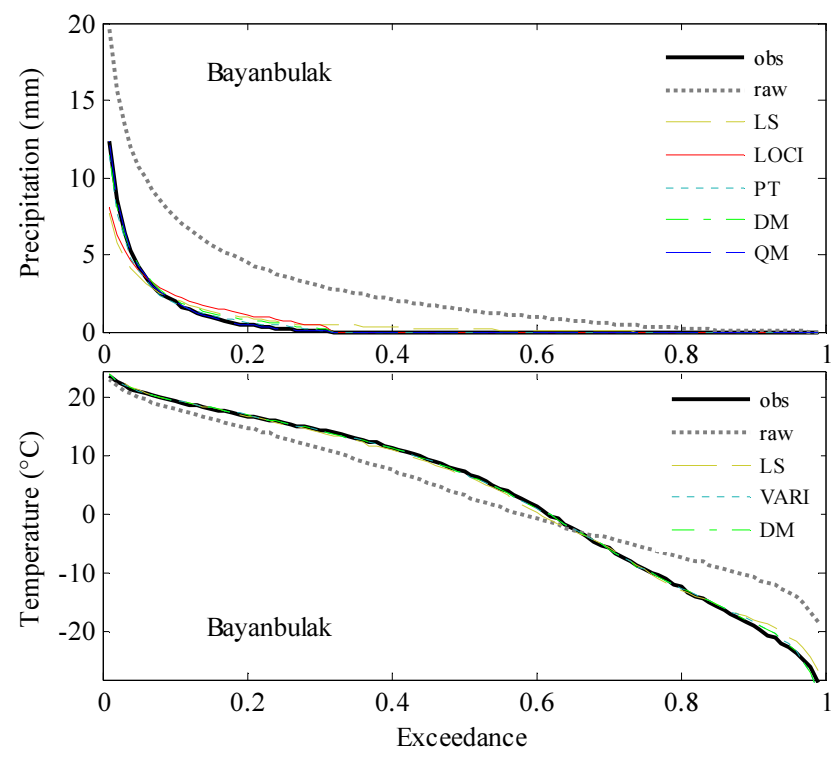

Figure 4. Exceedance probabilities of the observed (obs), raw, and bias-corrected precipitation (top) and temperature (bottom) at the Bayanbulak Station.

cipitation with probabilities below 0.06 and overestimates the low precipitation with probabilities between 0.06 and 0.32 . The overestimation of precipitation with probabilities between 0.32 and 0.73 indicates LS method has a very limited ability in reproducing dry day precipitation (below $0.1 \mathrm{~mm}$ ). Similar to LS method, the LOCI method also overestimates the low precipitation with probabilities between 0.08 and 0.32 and underestimates the high intensities with probabilities below 0.08 , which is in line with previous arguments by Berg et al. (2012). However, unlike the LS method, the LOCI method performs well on the estimation of the dry days with precipitation below $0.1 \mathrm{~mm}$. The PT, DM and QM methods well-adjust precipitation exceedance except that the DM method slightly overestimates the precipitation with probabilities between 0.12 and 0.28 . For temperature, the raw temperature overestimates low temperature with probabilities above 0.65 and underestimates high temperature with 
Table 5. Frequency-based statistics (unit: ${ }^{\circ} \mathrm{C}$ ) of daily observed (obs), raw RCM-simulated (raw) and bias-corrected maximum temperatures at the Bayanbulak Station.

\begin{tabular}{lrrrrr}
\hline & Mean & Median & $\begin{array}{r}\text { Standard } \\
\text { deviation }\end{array}$ & $\begin{array}{r}\text { 10th } \\
\text { percentile }\end{array}$ & $\begin{array}{r}\text { 90th } \\
\text { percentile }\end{array}$ \\
\hline obs & 3.08 & 7.20 & 14.50 & -18.70 & 19.20 \\
raw & 3.45 & 3.21 & 10.88 & -10.34 & 17.90 \\
LS & 3.08 & 6.65 & 14.14 & -17.33 & 19.40 \\
VARI & 3.08 & 6.85 & 14.50 & -17.76 & 19.36 \\
DM & 3.08 & 6.85 & 14.50 & -17.76 & 19.36 \\
\hline
\end{tabular}
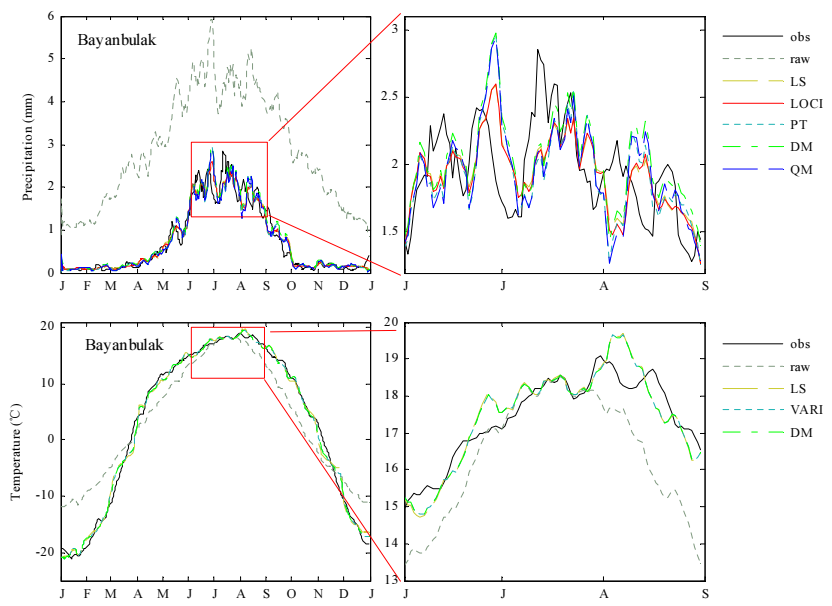

Figure 5. Daily mean precipitation and temperature of observed (obs), raw RCM-simulated (raw), and bias-corrected values at Bayanbulak Station, which were smoothed with the 7-day moving average method. The precipitation and temperature during MayAugust is amplified to inspect the performance of each correction method.

probabilities below 0.65 . All temperature correction methods adjust the biases in raw temperature and the corrected temperature has similar quantile values to the observations. They performed equally well and differences among these correction methods are negligible.

Time-series-based performances were evaluated and results are shown in Fig. 5 and Table 6. For precipitation, all bias correction methods significantly improve the raw RCM simulations. However, as shown in the right plot of Fig. 5, there is a systematic mismatch between observations and corrections which follow the pattern of the raw RCMsimulated precipitation, which indicates that all bias correction methods fail to correct the temporal pattern of precipitation. In addition, this mismatch differs between different methods, among which the differences are smaller for the LS and LOCI methods than for the PT, DM and QM methods. This resulted in slightly better squared-difference-based measures (e.g., NS, $R^{2}$ ) for LS and LOCI than for PT, DM and QM methods, as is indicated in Table 6. Similar to precipitation, all correction methods significantly improved the

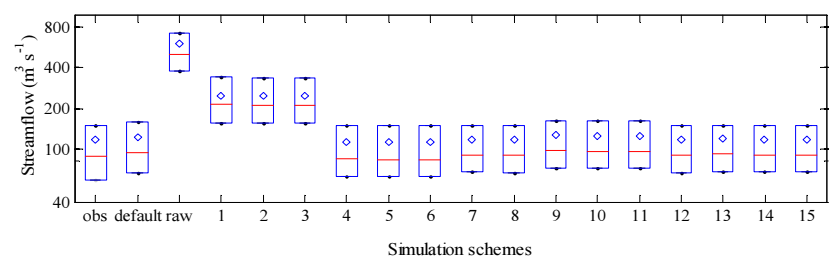

Figure 6. Box plots of observed (obs) and simulated daily streamflows using observed (default), raw RCM-simulated (raw) and corrected meteorological data (setup of simulations 1-15 are listed in Table 3). The mean values are shown with diamonds.

raw $\mathrm{RCM}$-simulated temperature. Biases in raw temperature (e.g., $1.1^{\circ} \mathrm{C}$ in spring, $1.0^{\circ} \mathrm{C}$ in summer, $3.3^{\circ} \mathrm{C}$ in autumn, and up to $7.6^{\circ} \mathrm{C}$ in winter) were corrected. These three correction methods performed equally well and no significant differences exist in terms of the average daily temperature graphs.

Table 6 lists the time-series-based metrics of corrected precipitation and temperature at the Bayanbulak Station. For precipitation, the performance of the raw RCM-simulated precipitation is very poor with $\mathrm{NS}=-6.78, P_{\mathrm{BIAS}}=$ $293.28 \%$ and $\mathrm{MAE}=65.40 \mathrm{~mm}$ for monthly data, and the improvements of correction are obvious. The $P_{\text {BIAS values }}$ of the corrected precipitation are within $\pm 7 \%$ and NS values approach 0.64. It is worth noting that the LS and LOCI methods perform better than the PT and QM methods in terms of time series performances. For temperature, although the raw RCM simulation obtains an acceptable NS value (0.84), it overestimates the observation with $P_{\mathrm{BIAS}}=15.78 \%$ and $\mathrm{MAE}=4.31{ }^{\circ} \mathrm{C}$. The $P_{\mathrm{BIAS}}$ values of the corrected temperatures are within $\pm 5 \%$ and NS values are over $94 \%$ (better than that of the raw) for all three correction methods and there is no significant difference between these results, which indicates the corrected monthly temperature series are in good agreement with the observation.

\subsection{Evaluation of streamflow simulations}

Figure 6 compares the mean, median, first and third quantiles of daily observed streamflows (obs), simulated streamflows using observed meteorological inputs (default), raw RCM 
Table 6. Time-series-based metrics of bias-corrected precipitation and temperature calculated on a monthly scale at the Bayanbulak Station.

\begin{tabular}{rrrrrr}
\hline & & & & & $\left.\begin{array}{r}\text { MAE } \\
(\mathrm{mm} \text { or }\end{array}{ }^{\circ} \mathrm{C}\right)$ \\
\hline Precipitation & raw & -6.78 & 293.28 & 0.42 & 65.40 \\
& LS & 0.64 & 0.06 & 0.65 & 9.66 \\
& LOCI & 0.61 & -0.71 & 0.64 & 10.14 \\
& PT & 0.42 & -0.09 & 0.53 & 11.98 \\
& DM & 0.46 & 6.64 & 0.56 & 11.78 \\
& QM & 0.44 & 0.03 & 0.54 & 11.99 \\
\hline Temperature & raw & 0.84 & 15.78 & 0.88 & 4.31 \\
& LS & 0.95 & 3.04 & 0.95 & 2.35 \\
& VARI & 0.94 & 4.78 & 0.94 & 2.52 \\
& DM & 0.94 & 4.74 & 0.94 & 2.52 \\
\hline
\end{tabular}

simulations (raw) and 15 combinations of corrected precipitation and corrected temperature (i.e., simulations 1-15). The overestimation of simulated streamflow using raw RCM simulations (i.e., raw) is obvious. Simulations 1-3 overestimate streamflow with $100 \%$ overestimation of the mean streamflow while simulations 4-15 reproduce similar streamflows as the observation or simulation default. The major difference between simulations $1-3$ and other simulations is that simulations 1 to 3 use the LS-corrected precipitation, which means precipitation corrected with the LS method has great bias in flow simulation in this study.

To investigate the performances of bias correction methods for different hydrological seasons, we divided the streamflow into two different periods according to the hydrograph (Fig. 3): The wet period is from April to September and the dry period is from October to March of the following year. It indicates that the performances of bias correction methods are, except for magnitudes, similar for both wet and dry periods (not shown), which demonstrates that the evaluation is robust and can provide useful information for both dry and wet seasons.

Figure 7 shows the exceedance probability curves (flow duration curves) of the observed streamflow (obs), and streamflows with simulation default and simulations 4-15. For plotting purposes, simulations raw and 1-3 are not shown. Generally, all simulations are in good agreement with the observation with probabilities between 0.12 and 0.72 , and precipitation correction methods have more significant influence than temperature correction methods. This confirms the previous sensitivity results that precipitation is the most sensitive driving force in streamflow simulation. Similar to performances of bias-corrected precipitation, simulations with DM-corrected precipitation (i.e., simulations 10 12) and LOCI-corrected precipitation (i.e., simulations 4-6) deviate the observation the most, these are followed by the PT and QM methods. All simulations encounter the problem to correctly mimic the low flow part (i.e., probabilities larger than 0.7). This might be a systematic problem of the

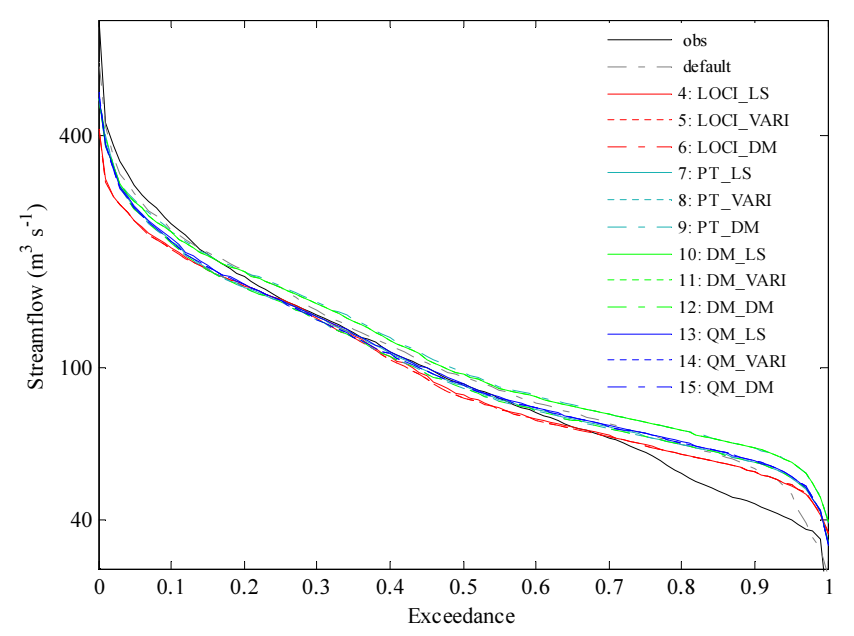

Figure 7. Exceedance probability curves of observed (obs) and simulated streamflow driven by observed (default), and bias-corrected meteorological data (numbers from 4 to 15 ; see Table 3 for detailed setup of these simulations).

calibrated hydrologic model (as indicated by simulation default), e.g., the objective function of the hydrological modeling is not focused on baseflow. Differences among streamflows driven by different temperature but same precipitation are insignificant, which is different from the study of Teutschbein and Seibert (2012). This may be related to the watershed characteristic.

The performances of simulation raw, simulations 1-15 at daily and monthly time steps (simulation default is taken as reference), are summarized in Table 3 . The raw is heavily biased with NS close to -56.3 and $P_{\mathrm{BIAS}}$ as large as $399 \%$ for monthly data. All the 15 simulations improve the statistics significantly. For simulations 1-3, whose precipitation series are corrected by the LS method, NS ranges from -3.09 to -2.85 for monthly streamflow and they substantially overestimate the streamflow with $P_{\text {BIAS }}$ over $100 \%$. For simulations $4-15$, monthly NS values are over 0.60 , which indi- 

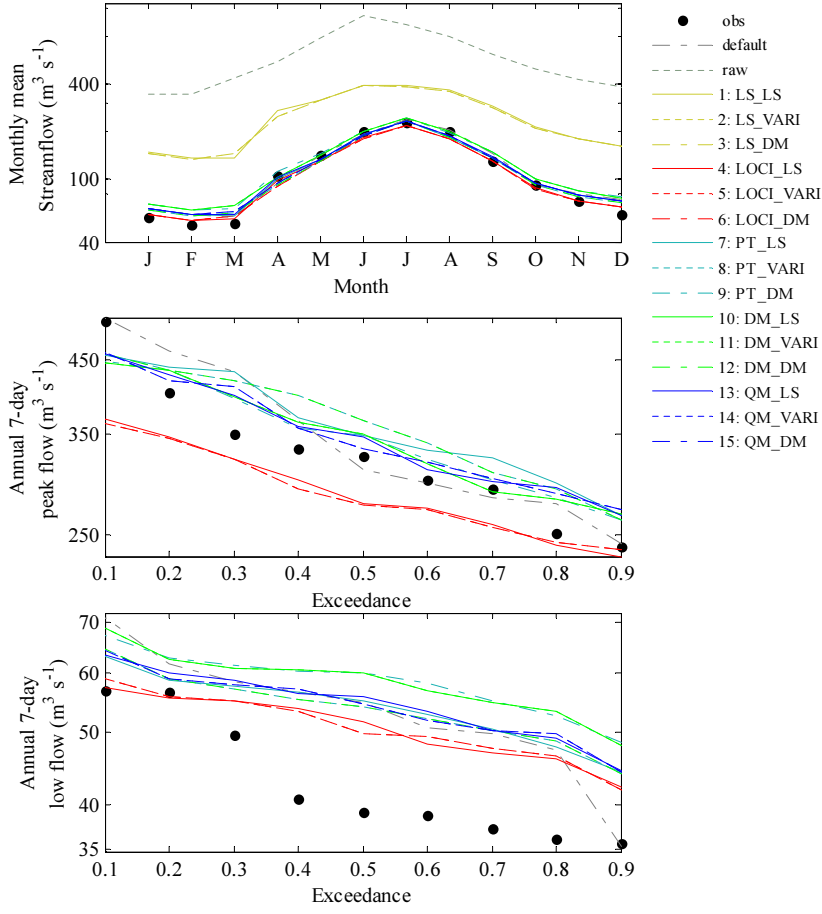

Figure 8. Monthly mean streamflow (top) and exceedance probability curves of annual 7-day peak flow (middle) and annual 7-day low flow (bottom) during 1986 2001 in the Kaidu River basin (obs: observed streamflow; default: simulated with observed meteorological data; raw: simulated with RCM-simulated meteorological data; 1-15: simulated with corrected RCM meteorological data listed in Table 3).

cates they can reproduce satisfactory monthly streamflows in this watershed, and simulations with precipitation corrected by LOCI (simulations 4-6) have the best NS and $P_{\mathrm{BIAS}}$ values. However, these indices of are lower for daily streamflow (NS values range from 0.38 to 0.50 ), and this is related to the mismatch between corrected and observed precipitation time series (see top plot in Fig. 5), which is intrinsic from the RCM model and cannot be improved through these correction methods.

It is worth noting that simulations $1-3$ and simulations $4-6$, whose precipitation is corrected by LS and LOCI, respectively, vary significantly. The difference between LS and LOCI is that LOCI introduces a threshold for precipitation on wet days to correct the wet-day probability while LS does not. That is a simple but quite pragmatic approach since the raw RCM-simulated precipitation usually has too many drizzle days (Teutschbein and Seibert, 2012). Obviously, wet-day probability is crucial to streamflow simulation when using elevation bands to account for spatial variation in SWAT (see more details in SWAT manual; http://www.brc.tamus.edu/).

Figure 8 shows the monthly mean streamflow and exceedance probability curves of 7-day peak flow and 7-day low flow. For the monthly mean streamflow, obviously the raw is heavily biased with deviations ranging from 282 to $426 \%$. Simulations $1-3$ also overestimate the observation and the default as discussed before, while simulations 4-15 reproduced good monthly mean streamflow. The annual peak flow and low flow are presented in Fig. 8 to investigate the impact of bias correction methods on extreme flows. For the peak flow, the exceedance probabilities of the simulations 4 15 are close to the observation while raw and simulations 1-3 deviate significantly (not shown). It is worth noting that simulations 4,5 and 6 , which perform the best in terms of the NS values, underestimate the peak flow by $1 \sim 28 \%$. The reason may be that the LOCI method adjusts all precipitation events in a certain month with a same scaling factor, which leads to the underestimation of the standard deviation and high precipitation intensity (Table 4), and finally results in an underestimation of the peak streamflow. For the low flow, all simulations overestimate the observation but are in good agreement with the default, which can be attributed to the systematic deficit in the hydrological model. The DM method slightly overestimates both peak flow and low flow. Results show slightly better performance of the PT and QM methods than LOCI and DM in predicting extreme flood and low flow, which is consistent with previous studies in North America and Europe (e.g., J. Chen et al., 2013; Teutschbein and Seibert, 2012).

\section{Conclusions}

The work presented in this study compared the abilities of five precipitation and three temperature correction methods in downscaling RCM simulations. The downscaled meteorological data were then used to model hydrologic processes in an arid region in China. The evaluation of the correction methods includes their abilities to reproduce precipitation, temperature and streamflow using a hydrological model driven by corrected meteorological variables. Several conclusions can be drawn.

1. Sensitivity analysis shows precipitation is the most sensitive driving force in streamflow simulation, followed by temperature and solar radiation, while relative humidity and wind speed are not sensitive.

2. Raw RCM simulations are heavily biased from observed meteorological data and this results in biases in the simulated streamflows which cannot be corrected through calibration of the hydrological model. However, all bias correction methods effectively improve precipitation, temperature, and streamflow simulations.

3. Different precipitation correction methods show a big difference in downscaled precipitations while different temperature correction methods show similar results in downscaled temperatures. For precipitation, the PT and QM methods performed equally best in terms of the 
frequency-based indices; while the LOCI method performed best in terms of the time-series-based indices.

4. For simulated streamflow, precipitation correction methods have a more significant influence than temperature correction methods and their performances on streamflow simulations are consistent with these of corrected precipitation; i.e., the PT and QM methods performed equally best in correcting the flow duration curve and peak flow while the LOCI method performed best in terms of the time-series-based indices. Note the LOCI and DM methods should be used with caution when analyzing drought or extreme streamflows because the LOCI method may underestimate the extreme precipitation and the DM method performs ineffectively when either simulated precipitation or observed precipitation does not follow the proposed distribution. Moreover, the LS method is not suitable in hydrological impact assessments where there is a large variation in precipitation distribution and few meteorological stations are used since LS fails to correct wet-day probability.

Generally, selection of the precipitation correction method is more important than selection of the temperature correction method to downscale GCM/RCM simulations and thereafter for streamflow simulations. This might be generally true for other regional studies as GCMs/RCMs normally tend to better represent the temperature field than the precipitation field. However, the selection of a precipitation correction method will be case dependent. The comparison procedure listed in Fig. 2 can be applied for other cases.

Acknowledgements. The research was supported by the Thousand Youth Talents plan (Xinjiang Project), the National Natural Science Foundation of China (41471030), and the Foundation of State Key Laboratory of Desert and Oasis Ecology (Y371163). We would like to thank Xuejie Gao at the National Climate Center (China) for providing the output of the Regional Climate Model used in this paper. The authors would like to thank reviewer Markus Muerth and an anonymous reviewer for their valuable comments and suggestions.

Edited by: B. Schaefli

\section{References}

Ahmed, K. F., Wang, G., Silander, J., Wilson, A. M., Allen, J. M., Horton, R., and Anyah, R.: Statistical downscaling and bias correction of climate model outputs for climate change impact assessment in the US northeast, Global Planet. Change, 100, 320332, 2013.

Anderson Jr., W. P., Storniolo, R. E., and Rice, J. S.: Bank thermal storage as a sink of temperature surges in urbanized streams, J. Hydrol., 409, 525-537, doi:10.1016/j.jhydrol.2011.08.059, 2011.
Arnell, N. W.: Factors controlling the effects of climate change on river flow regimes in a humid temperate environment, J. Hydrol., 132, 321-342, doi:10.1016/0022-1694(92)90184-W, 1992.

Arnold, J. G. and Fohrer, N.: SWAT2000: current capabilities and research opportunities in applied watershed modelling, Hydrol. Process., 19, 563-572, doi:10.1002/hyp.5611, 2005.

Arnold, J. G., Srinivasan, R., Muttiah, R. S., and Williams, J.: Large area hydrologic modeling and assessment part I: Model development1, JAWRA J. Am. Water Resour. Assoc., 34, 73-89, 1998.

Arnold, J., Muttiah, R., Srinivasan, R., and Allen, P.: Regional estimation of base flow and groundwater recharge in the Upper Mississippi river basin, J. Hydrol., 227, 21-40, 2000.

Berg, P., Feldmann, H., and Panitz, H. J.: Bias correction of high resolution regional climate model data, J. Hydrol., 448, 80-92, 2012.

Bergstrom, S., Carlsson, B., Gardelin, M., Lindstrom, G., Pettersson, A., and Rummukainen, M.: Climate change impacts on runoff in Sweden-assessments by global climate models, dynamical downscaling and hydrological modelling, Clim. Res., 16, 101-112, 2001.

Block, P. J., Souza Filho, F. A., Sun, L., and Kwon, H. H.: A Streamflow Forecasting Framework using Multiple Climate and Hydrological Models1, JAWRA J. Am. Water Resour. Assoc., 45, 828843, 2009.

Buytaert, W., Vuille, M., Dewulf, A., Urrutia, R., Karmalkar, A., and Célleri, R.: Uncertainties in climate change projections and regional downscaling in the tropical Andes: implications for water resources management, Hydrol. Earth Syst. Sci., 14, 12471258, doi:10.5194/hess-14-1247-2010, 2010.

Chen, J., Brissette, F. P., Chaumont, D., and Braun, M.: Finding appropriate bias correction methods in downscaling precipitation for hydrologic impact studies over North America, Water Resour. Res., 49, 4187-4205, doi:10.1002/wrcr.20331, 2013.

Chen, Y., Xu, C., Chen, Y., Li, W., and Liu, J.: Response of glaciallake outburst floods to climate change in the Yarkant River basin on northern slope of Karakoram Mountains, China, Quaternary Int., 226, 75-81, 2010.

Chen, Y., Du, Q., and Chen, Y.: Sustainable water use in the Bosten Lake Basin, Science press, Beijing, 329 pp., 2013.

Chen, Z., Chen, Y., and Li, B.: Quantifying the effects of climate variability and human activities on runoff for Kaidu River Basin in arid region of northwest China, Theor. Appl. Climatol., 111, 537-545, 2013.

Elguindi, N., Somot, S., Déqué, M., and Ludwig, W.: Climate change evolution of the hydrological balance of the Mediterranean, Black and Caspian Seas: impact of climate model resolution, Clim. Dynam., 36, 205-228, 2011.

Fang, G., Yang, J., Chen, Y., and Xu, C.: Contribution of meteorological input in calibrating a distributed hydrologic model with the application to a watershed in the Tianshan Mountains, China, Environ. Earth Sci., doi:10.1007/s12665-015-4244-7, in press, 2015.

Fowler, H. J., Ekström, M., Blenkinsop, S., and Smith, A. P.: Estimating change in extreme European precipitation using a multimodel ensemble, J. Geophys. Res., 112, D18104, doi:10.1029/2007JD008619, 2007.

Gao, X., Wang, M., and Giorgi, F.: Climate change over China in the 21st century as simu-lated by BCC_CSM1. 1-RegCM4. 0, Atmos. Oceanic Sci. Lett., 6, 381-386, 2013. 
Giorgi, F.: Simulation of regional climate using a limited area model nested in a general circulation model, J. Climate, 3, 941-963, 1990.

Giorgi, F. and Mearns, L. O.: Introduction to special section: Regional climate modeling revisited, J. Geophys. Res.-Atmos., (1984-2012), 104, 6335-6352, 1999.

Graham, L. P., Andréasson, J., and Carlsson, B.: Assessing climate change impacts on hydrology from an ensemble of regional climate models, model scales and linking methods-a case study on the Lule River basin, Clim. Change, 81, 293-307, 2007.

Lenderink, G., Buishand, A., and van Deursen, W.: Estimates of future discharges of the river Rhine using two scenario methodologies: direct versus delta approach, Hydrol. Earth Syst. Sci., 11, 1145-1159, doi:10.5194/hess-11-1145-2007, 2007.

Li, B., Chen, Y., and Shi, X.: Why does the temperature rise faster in the arid region of northwest China?, J. Geophys. Res., 117, D16115, doi:10.1029/2012JD017953, 2012.

Liu, T., Willems, P., Pan, X. L., Bao, An. M., Chen, X., Veroustraete, F., and Dong, Q. H.: Climate change impact on water resource extremes in a headwater region of the Tarim basin in China, Hydrol. Earth Syst. Sci., 15, 3511-3527, doi:10.5194/hess-15-35112011, 2011.

Liu, Z., Xu, Z., Huang, J., Charles, S. P., and Fu, G.: Impacts of climate change on hydrological processes in the headwater catchment of the Tarim River basin, China, Hydrol. Process., 24, 196208, doi:10.1002/hyp.7493, 2010.

Maraun, D., Wetterhall, F., Ireson, A. M., Chandler, R. E., Kendon, E. J., Widmann, M., Brienen, S., Rust, H. W., Sauter, T., Themeß1, M., Venema, V. K. C., Chun, K. P., Goodess, C. M., Jones, R. G., Onof, C., Vrac, M., and Thiele-Eich, I.: Precipitation downscaling under climate change: recent developments to bridge the gap between dynamical models and the end user, Rev. Geophys., 48, RG3003, doi:10.1029/2009RG000314, 2010.

Mehrotra, R. and Sharma, A.: An improved standardization procedure to remove systematic low frequency variability biases in GCM simulations, Water Resour. Res., 48, W12601, doi:10.1029/2012WR012446, 2012.

Murphy, J.: An evaluation of statistical and dynamical techniques for downscaling local climate, J. Climate, 12, 2256-2284, 1999.

Nash, J. E. and Sutcliffe, J.: River flow forecasting through conceptual models part I - A discussion of principles, J. Hydrol., 10, 282-290, 1970.

Piani, C., Haerter, J., and Coppola, E.: Statistical bias correction for daily precipitation in regional climate models over Europe, Theor. Appl. Climatol., 99, 187-192, 2010.

Schmidli, J., Frei, C., and Vidale, P. L.: Downscaling from GC precipitation: A benchmark for dynamical and statistical downscaling methods, Int. J. Climatol., 26, 679-689, doi:10.1002/joc.1287, 2006.

Seager, R. and Vecchi, G. A.: Greenhouse warming and the 21st century hydroclimate of southwestern North America, Proc. Natl. Acad. Sci. USA, 107, 21277-21282, doi:10.1073/pnas.0910856107, 2010.
Setegn, S. G., Rayner, D., Melesse, A. M., Dargahi, B., and Srinivasan, R.: Impact of climate change on the hydroclimatology of Lake Tana Basin, Ethiopia, Water Resour. Res., 47, W04511, doi:10.1029/2010WR009248, 2011.

Shen, Y. and Chen, Y.: Global perspective on hydrology, water balance, and water resources management in arid basins, Hydrol. Process., 24, 129-135, 2010.

Sobol', I. M.: Global sensitivity indices for nonlinear mathematical models and their Monte Carlo estimates, Math. Comput. Simulat., 55, 271-280, doi:10.1016/s0378-4754(00)00270-6, 2001.

Sun, F., Roderick, M. L., Lim, W. H., and Farquhar, G. D.: Hydroclimatic projections for the Murray-Darling Basin based on an ensemble derived from Intergovernmental Panel on Climate Change AR4 climate models, Water Resour. Res., 47, W00G02, doi:10.1029/2010wr009829, 2011.

Terink, W., Hurkmans, R. T. W. L., Torfs, P. J. J. F., and Uijlenhoet, R.: Evaluation of a bias correction method applied to downscaled precipitation and temperature reanalysis data for the Rhine basin, Hydrol. Earth Syst. Sci., 14, 687-703, doi:10.5194/hess-14-6872010, 2010.

Teutschbein, C. and Seibert, J.: Bias correction of regional climate model simulations for hydrological climate-change impact studies: Review and evaluation of different methods, J. Hydrol., 456, 12-29, doi:10.1016/j.jhydrol.2012.05.052, 2012.

Themeß1, M. J., Gobiet, A., and Leuprecht, A.: Empirical - statistical downscaling and error correction of daily precipitation from regional climate models, Int. J. Climatol., 31, 1530-1544, 2011.

Themeß1, M. J., Gobiet, A., and Heinrich, G.: Empirical-statistical downscaling and error correction of regional climate models and its impact on the climate change signal, Clim. Change, 112, 449468, 2012.

Thom, H. C.: A note on the gamma distribution, Mon. Weather Rev., $86,117-122,1958$.

Wang, H., Chen, Y., Li, W., and Deng, H.: Runoff responses to climate change in arid region of northwestern China during 1960 2010, Chinese Geogr. Sci., 23, 286-300, 2013.

Wilcke, R. A. I., Mendlik, T., and Gobiet, A.: Multi-variable error correction of regional climate models, Clim. Change, 120, 871887, 2013.

Wu, T., Li, W., Ji, J., Xin, X., Li, L., Wang, Z., Zhang, Y., Li, J., Zhang, F., and Wei, M.: Global carbon budgets simulated by the Beijing Climate Center Climate System Model for the last century, J. Geophys. Res.-Atmos., 118, 4326-4347, 2013.

Xin, X., Wu, T., Li, J., Wang, Z., Li, W., and Wu, F.: How well does BCC_CSM1. 1 reproduce the 20th century climate change over China, Atmos. Oceanic Sci. Lett., 6, 21-26, 2013.

$\mathrm{Xu}, \mathrm{C}$. , Chen, Y., Chen, Y., Zhao, R., and Ding, H.: Responses of Surface Runoff to Climate Change and Human Activities in the Arid Region of Central Asia: A Case Study in the Tarim River Basin, China, Environ. Manage., 51, 926-938, 2013. 